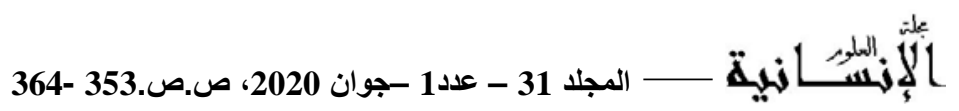

\title{
الحماية القانونية الداخلية للعلامة التجارية
}

Internal legal protection of the trademark

تاريخ الاستلام : 2019/11/11 ؛ تاريخ القبول : 2020/04/04

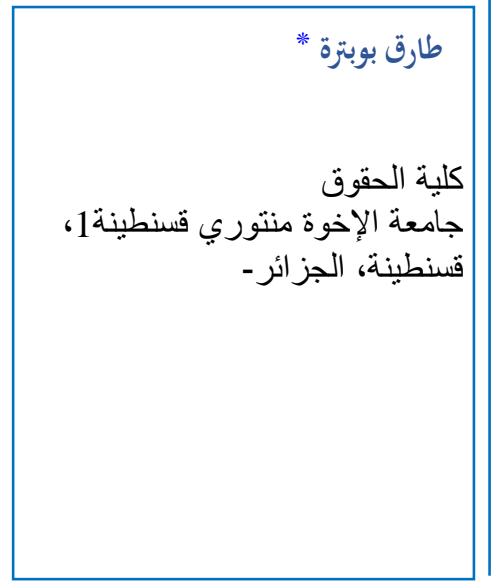

\section{Abstract}

A trademark is one of the most important elements of intellectual property in general and industrial property in particular, a signal that traders place to distinguish their goods or services from those of other goods and services, thereby making the consumer prefer a good or service from the other, thus achieving significant financial gains, and Through this feature, the trademark has become the target of imitators for material gain, which led to the State to recognize the domestic legal protection through the order 03-06 on trademarks as a result of attacks on them from imitation and misleading to harm the consumer and the right holder and State all either.

Keywords: Marks ; unfair competition suit; counterfeiting suit.

\section{Résumé}

Une marque est l'un des éléments les plus importants de la propriété intellectuelle en général et de la propriété industrielle en particulier, un signal que les commerçants placent pour distinguer leurs produits ou leurs services de leurs homologues, ce qui fait que le consommateur préfère un produit plutôt que l'autre et réalise ainsi des gains financiers importants. La marque est devenue la cible des imitateurs afin de limiter les gains matériels, ce qui a conduit l'État à approuver la protection juridique nationale par le biais de l'ordonnance 03-06 sur les marques suite à des attaques visant à les imiter et à induire en erreur afin de nuire au consommateur, au titulaire du droit et à l'État.

Mots clés: La marque ; propriété industrielle ; Consommateur.

* Corresponding author, e-mail: boubetra.tarek@outlook.fr 


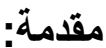

غير خفي أن الحقوق جميعا تحتاج إلى الحماية و هذه الحماية هي التي تعطي للحق

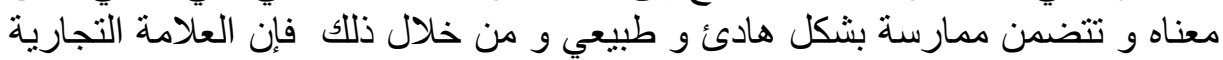
و هي كأحد حقوق الملكية الصناعية تحتاج إلى مثل هذه فئ الحماية التي تكلفها التشريعات

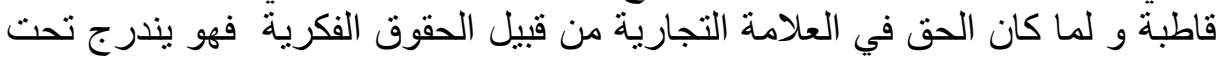
مظلة هذه الحماية نتيجة لطبيعتها الإستئنارية.

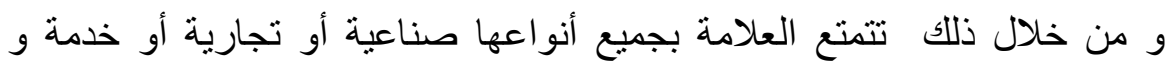

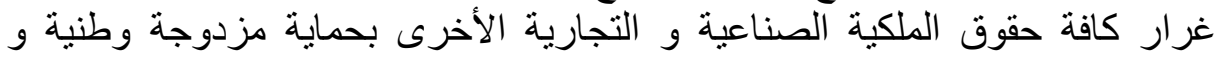

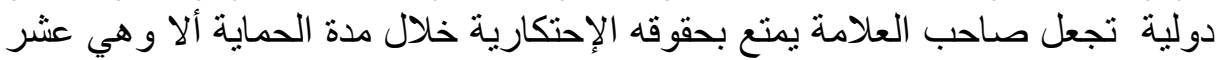
سنوات.و من ثم تحمي حقوق صاحب العلامة داخل التراب الوطني و خلاردة خلارجه حيث يجاوز استغلال العلامة في بعض الأحيان الحفان حدود إقليم البلاد.

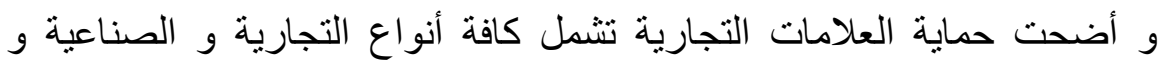

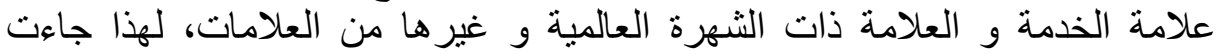
الحماية القانونية الداخلية كوسيلة لحماية حقوق صاحة العاد العلامة. و من خلال هذا الطرح تتجلي الاشكالية في:

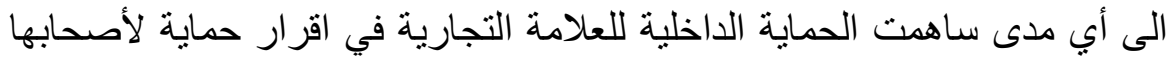

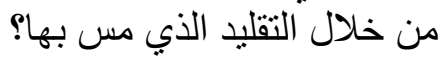
المبحث الأول: الحماية المدنية للعلامة التجارية التهاية

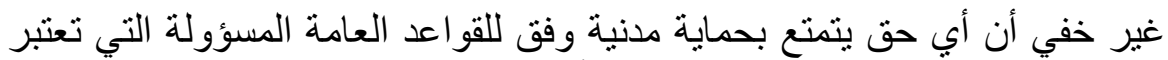

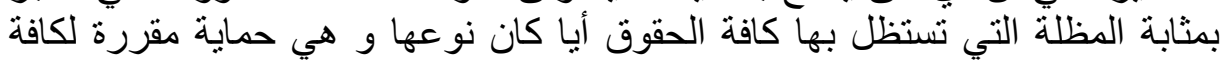

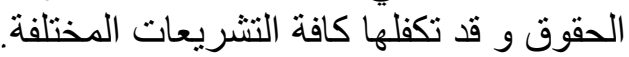

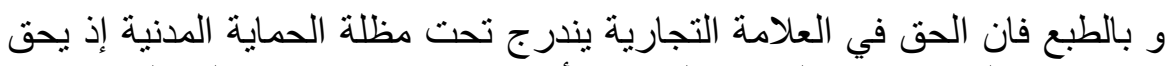

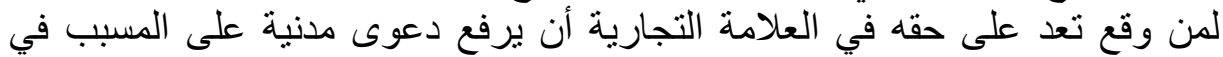

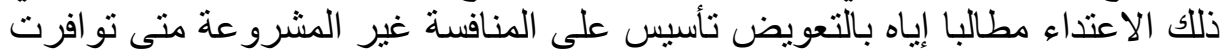

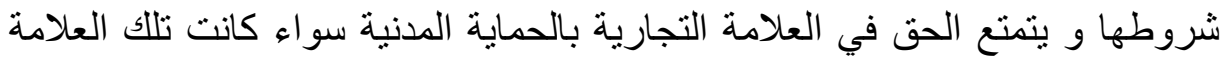

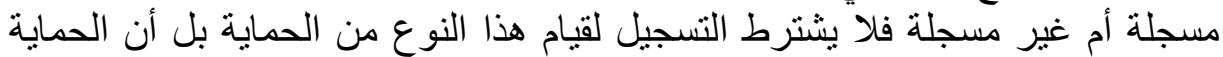
المدنية تعنبر الوسيلة الوحيدة لحماية ملكية العلامة التجارية منى كانت الته هذه الأخيرة

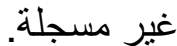

المطلب الأول: دعوى المنافسة غير مشروعة

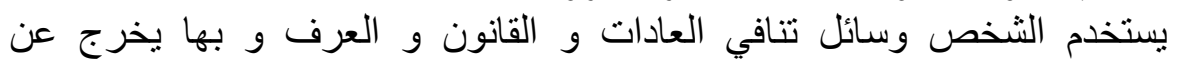

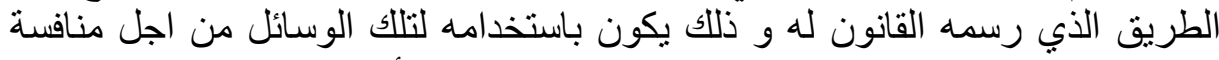

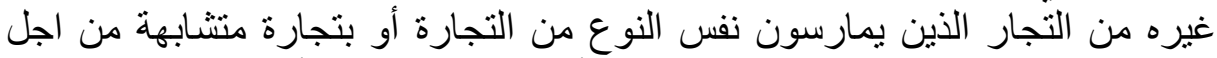

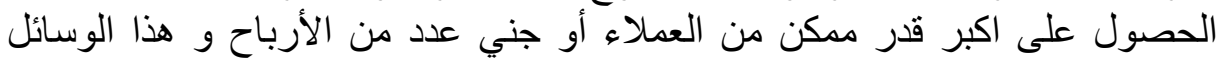

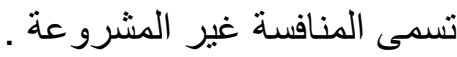

$$
\begin{aligned}
& \text { الفرع الأول: مفهوم المنافسة غير مشروعة الفرة }
\end{aligned}
$$

ولقد وردت عدة مفاهيم توضح معنى المنافسة غير المشروعة في مجال الفقه و مور

نذكر منها : نان

" المنافسة غير المشروعة هي التي تتحقق باستخدام التاجر لوسائل منافية للعادات

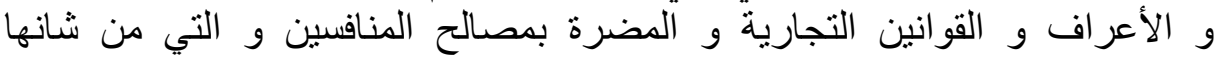
التشويش على السمعة التجارية و إثارة الثك حول جودة منتجاته لنزع الثن الثقة من منشاته

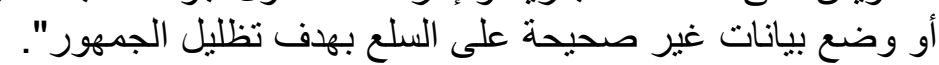
" استخدام التاجر لطرق منافية للقانون أو العادات أو مبادئ الثرفئ الثرف و الأمانة في

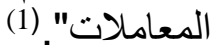




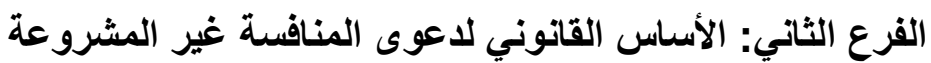

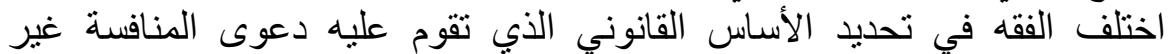

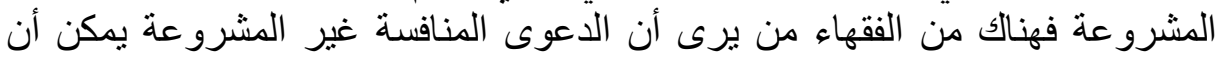

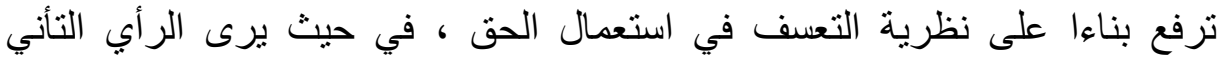

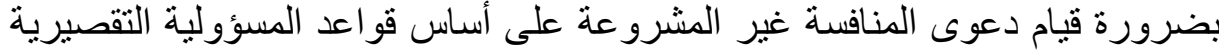

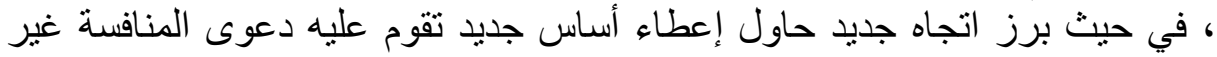

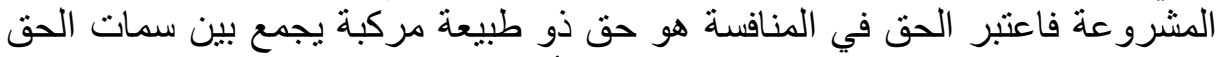

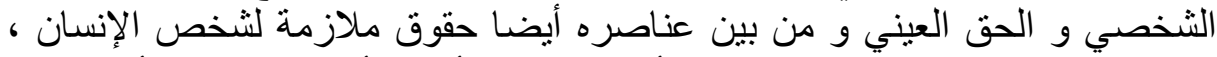

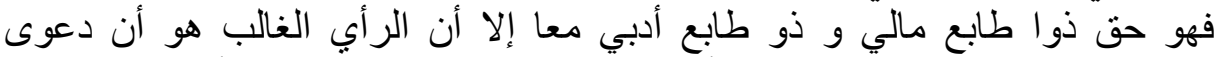

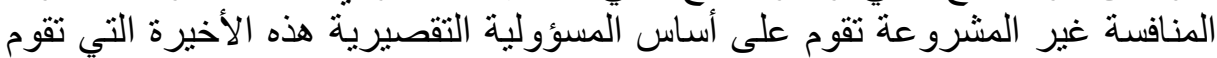

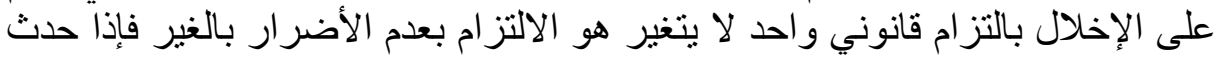

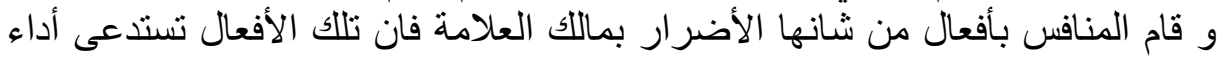

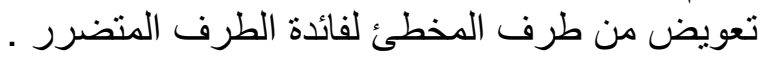

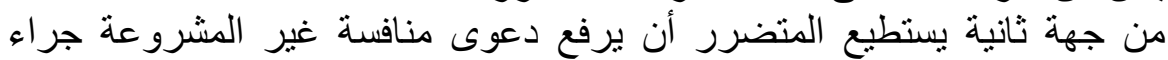

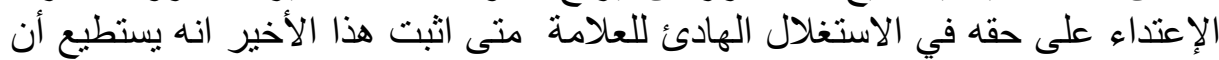

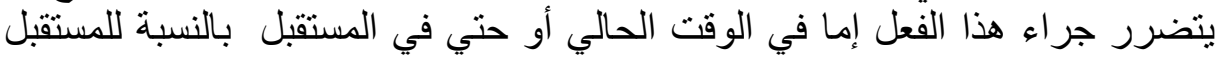

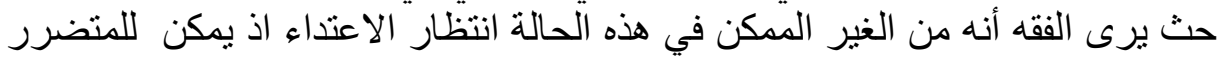

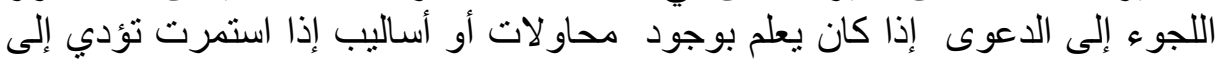

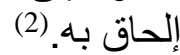

أولا: القضاء المختص بالنظر في دعوى المنافسة غير المشروعة

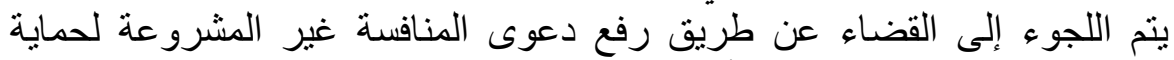

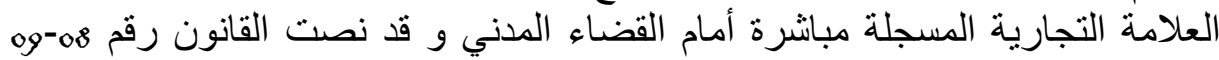

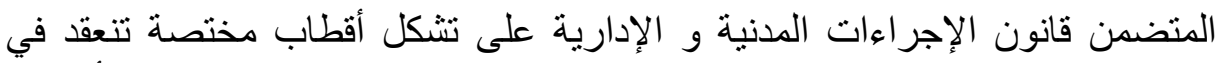

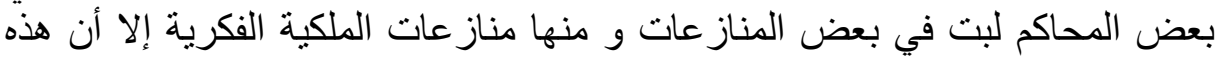

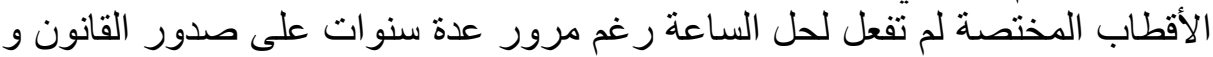

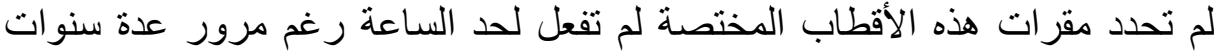

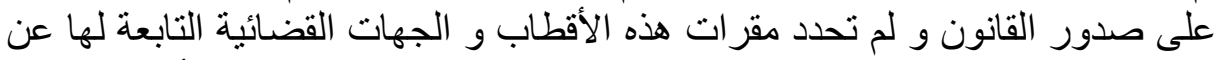

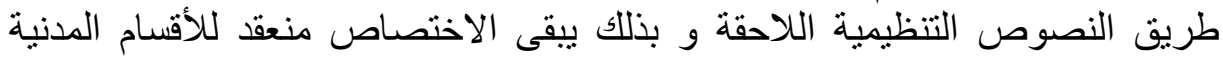

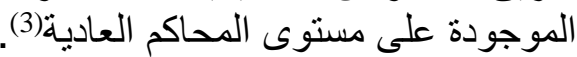
ثانيا: شروط دعوى المنافسة

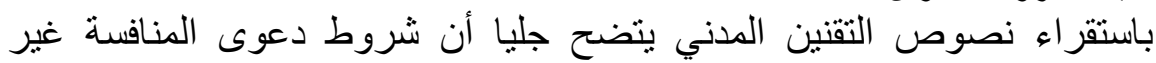

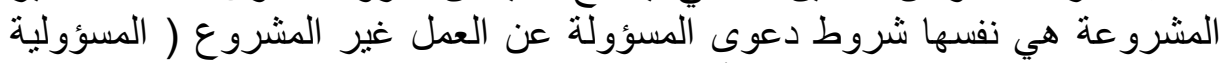

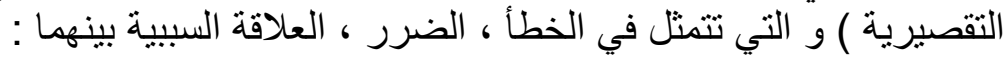

$$
\text { : 1 الخطأ }
$$

لم تعرف القوانين الخطأ عند تنظيمها للمسؤولية عن العمل غير المشروع بل تركت ذللك للفقه و القضاء. و الخطأ كما استقر عليه الرأي فقها و قضاء هو " إخلال بواجب قانوني مقترن

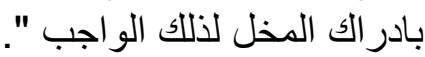

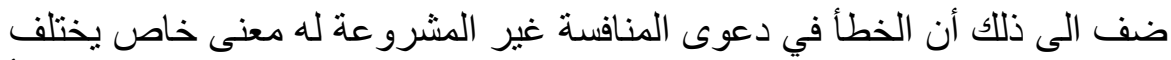

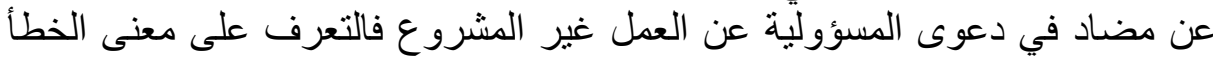

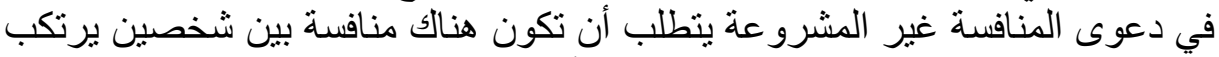

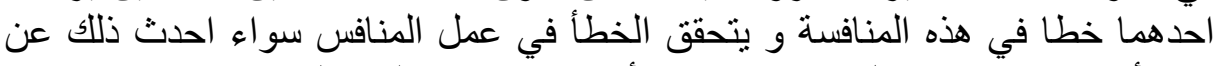

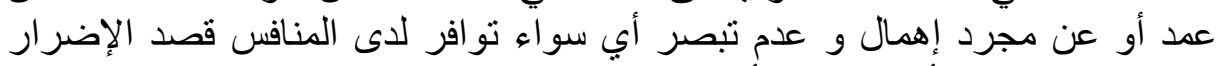
بالغير و سواء النية أو كان الخطأ غير عمدي مبعثه الإهمال بحقيقة المنافس. 
و المعيار الذي استقر عليه الرأي فقها و قضاء في تحديد معنى الخطأ هو القيام

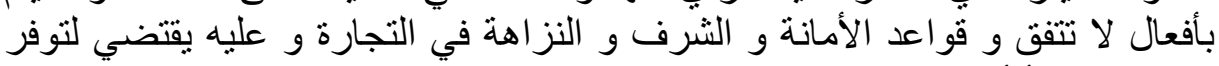

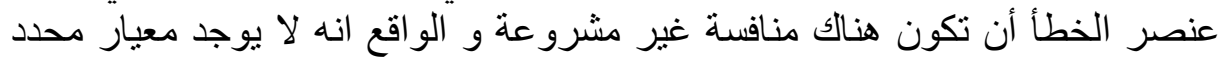

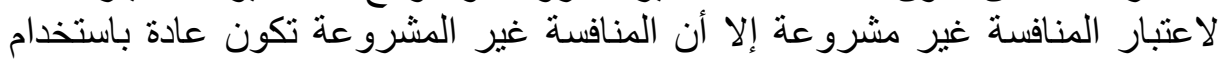

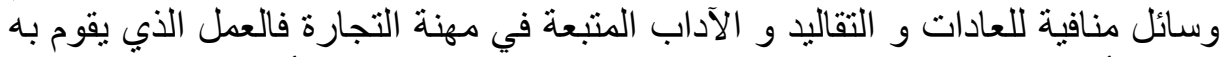

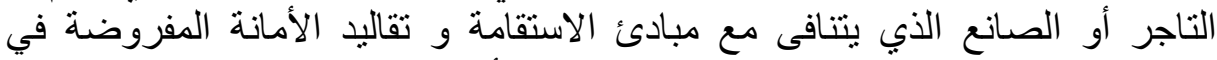

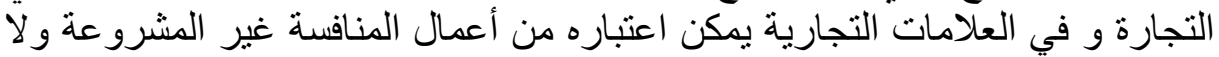

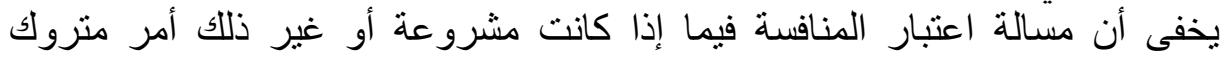

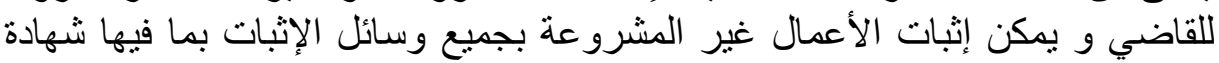

الثهود و القر ائن(4).

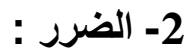

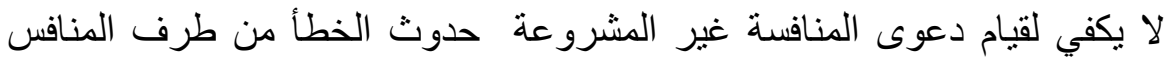

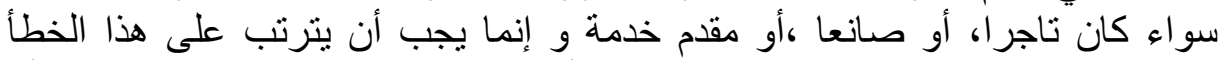

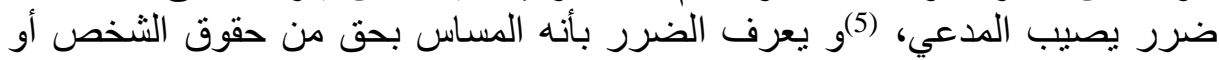
بمصلحة مشرو عة له له و يستوي أن يكون الضرر ماديا ينصب على على حق من الحقوق المالية مثل الخسارة

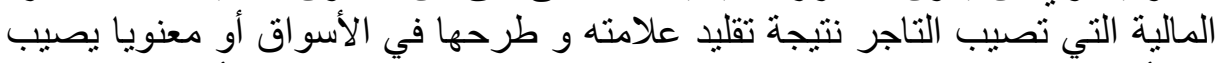

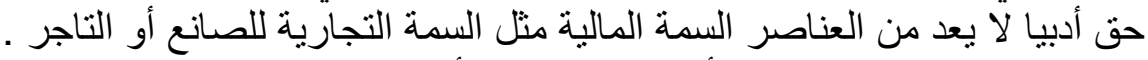

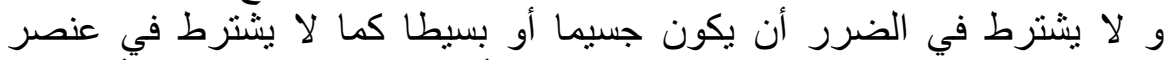

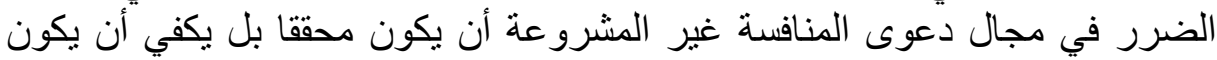

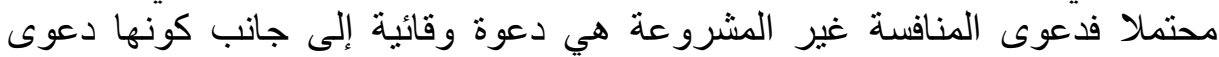

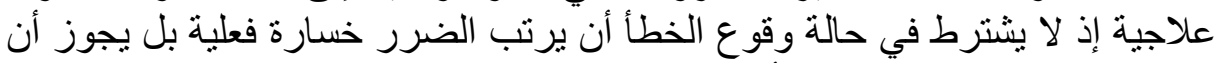

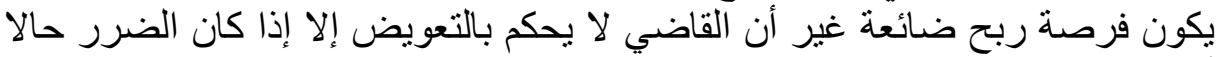

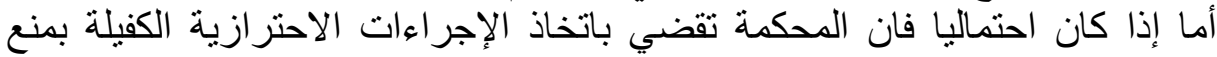

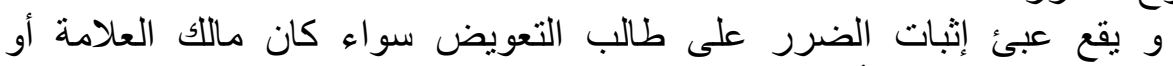

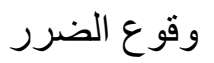

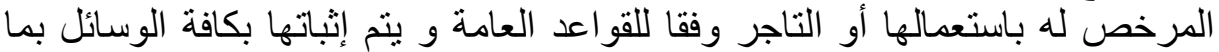

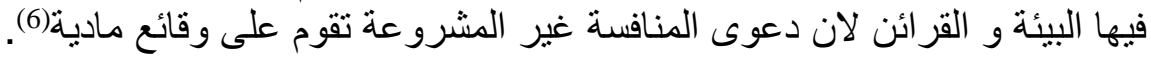

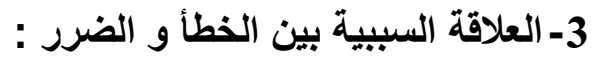

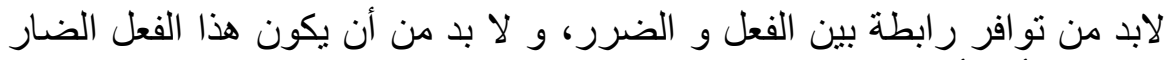

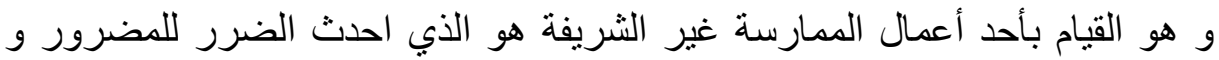

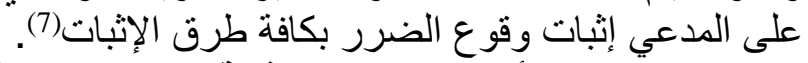

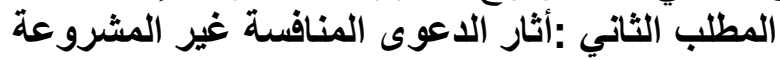

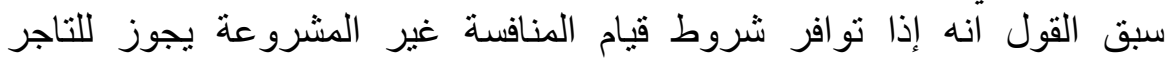

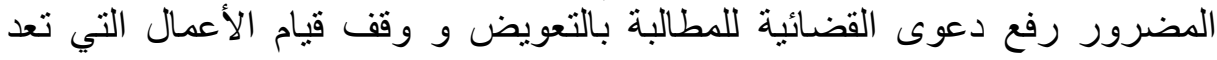

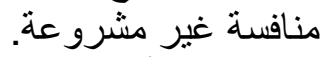

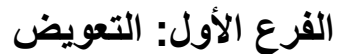

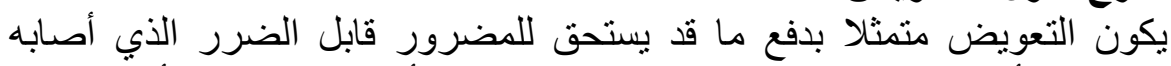

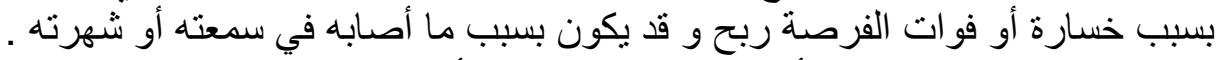

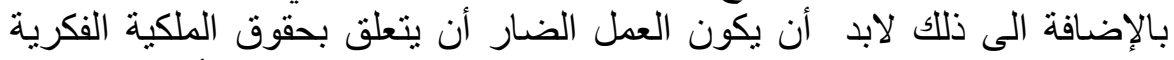

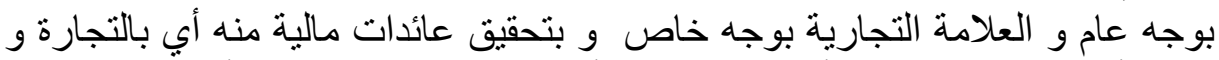

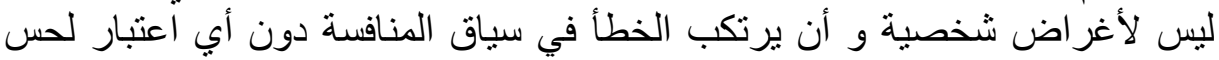




$$
\text { 1النية أو غير هاو ينقسم التعويض على قيام ضرر في(8) }
$$

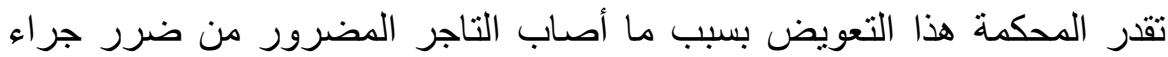

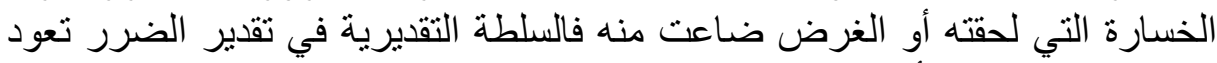

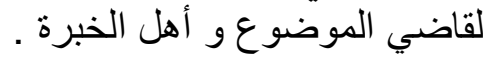

$$
\text { 2- التعويض عن الضرر المعنوي }
$$

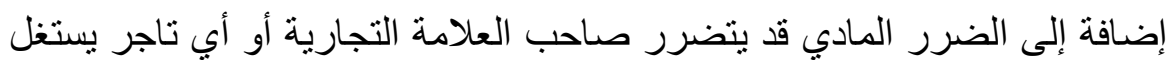

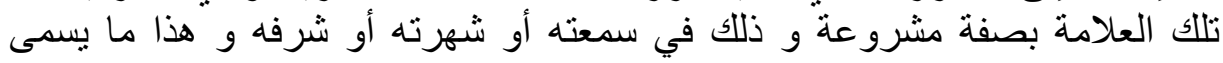

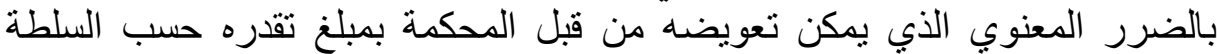

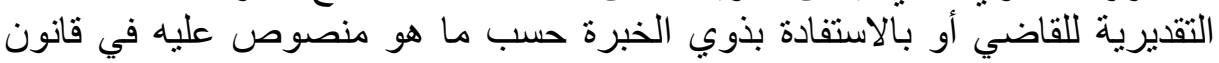

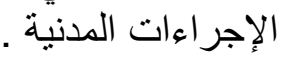

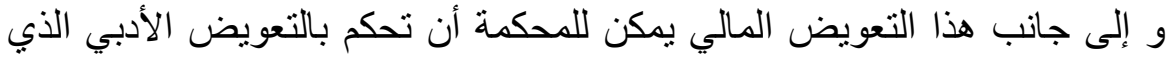
يمثل في نشر الحكم على نفقة المحكوم إذ تنص المادة 34 من الأمر رقم

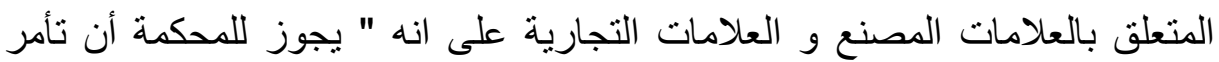

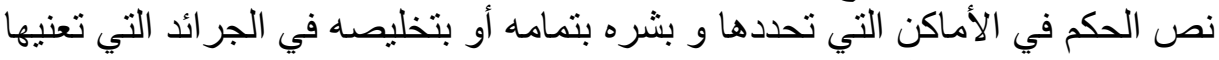
و ذللك كله على نفقة المحكوم".

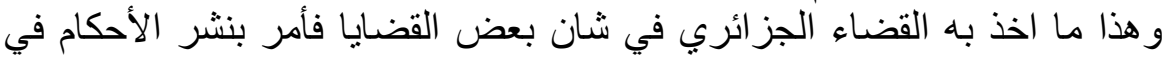

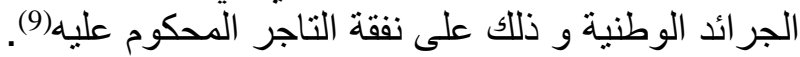

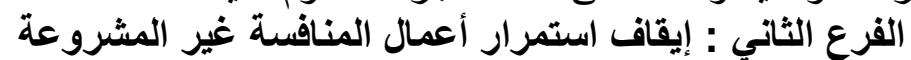

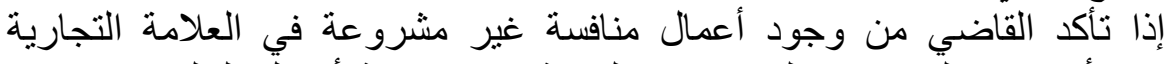

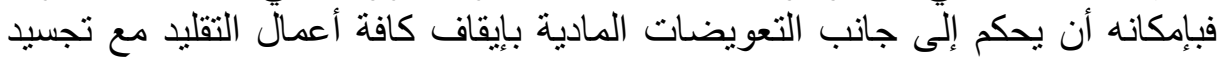

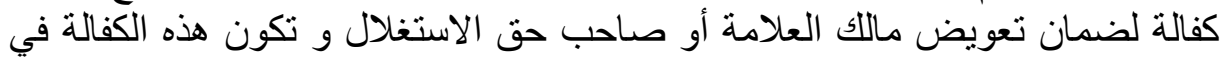

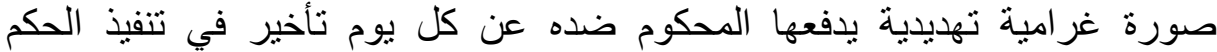

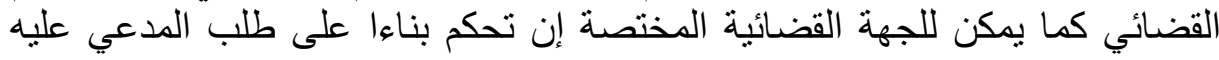
بإبطال أو إلغاء تسجيل العلامة المقلدة أعمالا لنص المادة 30 من ذات الماته الأمر . كما قضت الفقرة 2 من المادة 29 من الأمر 03-06 المتعلق بالعلامات انه بإمكان

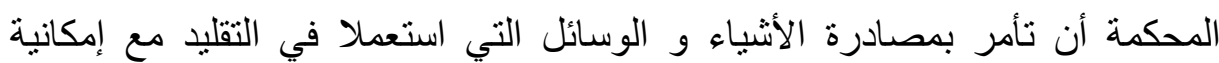

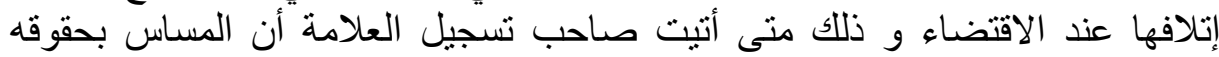
أصبح وشيكا. أما فيما يتعلق بالإجراءات التي تضمن وقف أعمال المنافسة غير المشروعة

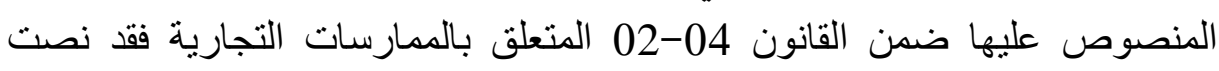
المادة 39 منه على إمكانية حجز البضائع موضوع المخالفات المنصوص عليها ضمن

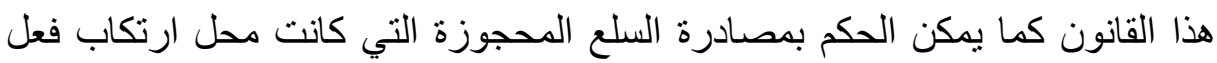
التقليد (10).

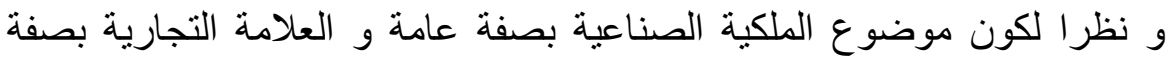

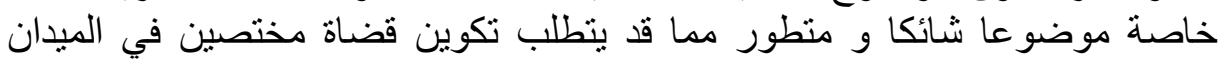

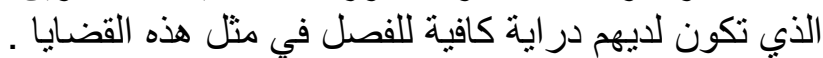

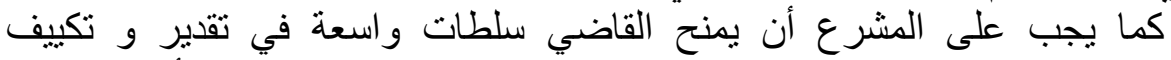

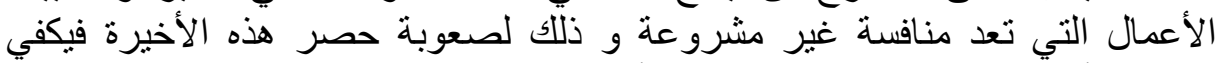

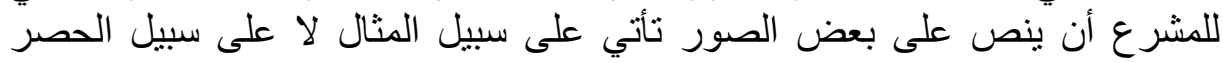

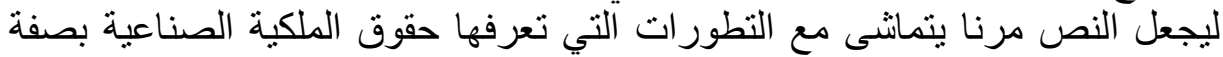




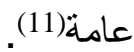

المبحث الثاني: الحماية الجزائية

تتفق التشريعات المقارنة على أنى النماية الحماية الجزائية لا تشمل سوى العلامة التجارية

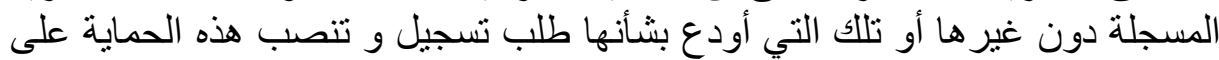

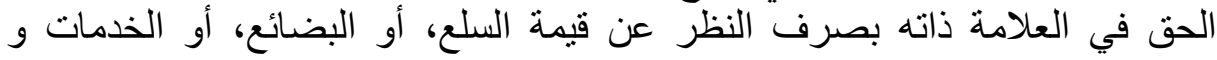

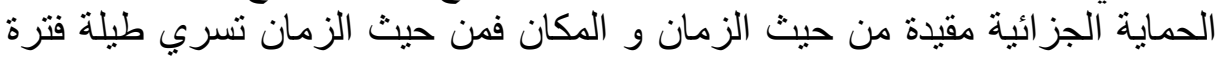

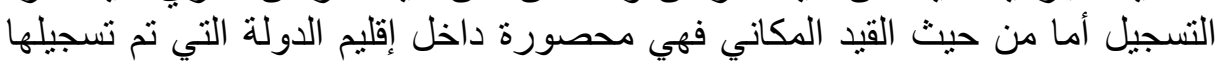
فيها إلا إذا كانت الدولة طرفا في الاتفاقيات الدولية.

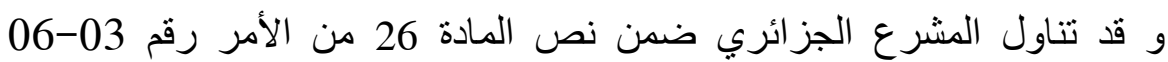

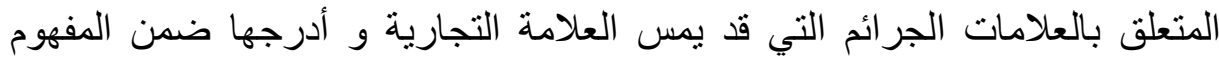

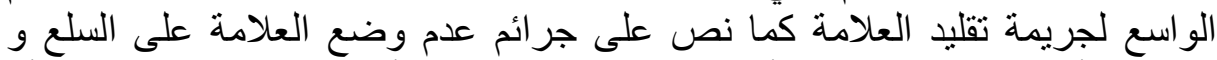

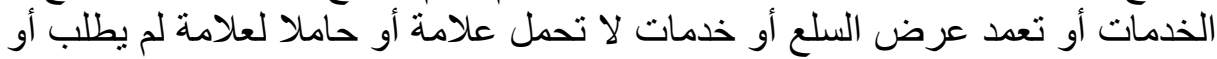

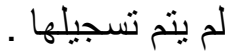

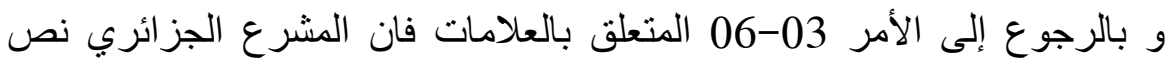

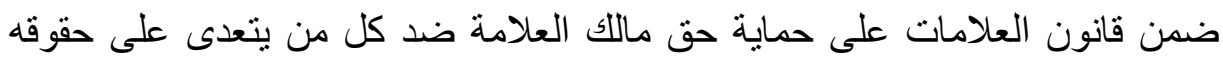

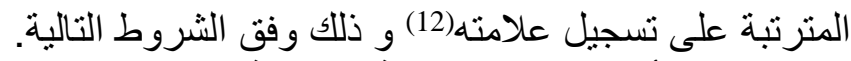

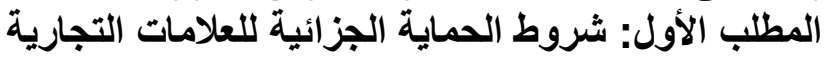

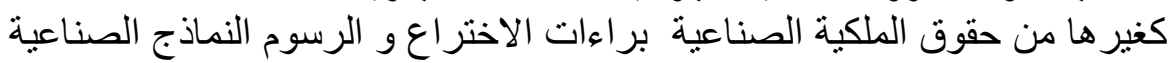

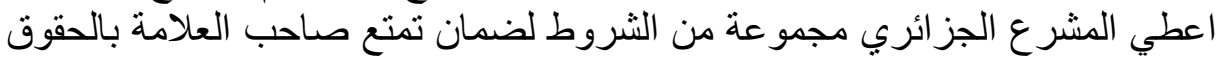

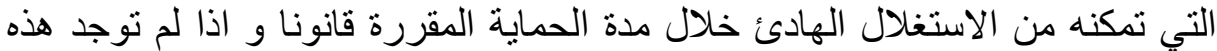

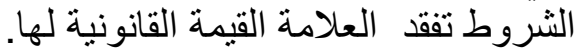
الفرع الأول: الحماية الجزائية مقصورة على العلى العلامة التجارية المسجلة دون

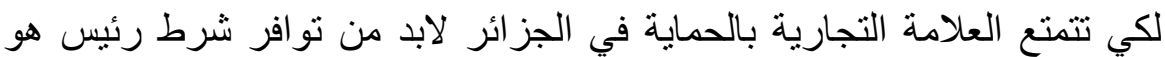
غيرها

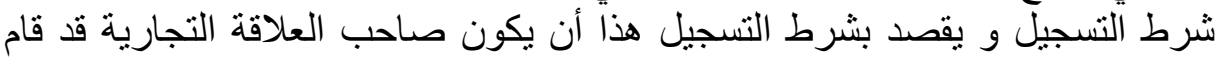

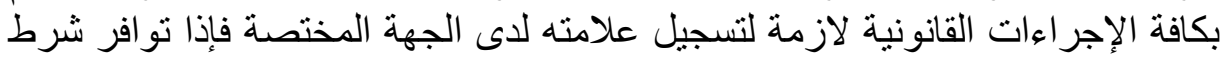
التسجيل قامت الحماية الجزائية للعلامة و أصبح التعدي عليها يشكل جريمة يعاقب التباتي

الفرع الثاني: الحماية الجزائية تنصب على ذات الحق في العلامة التجارية عليها القانون.

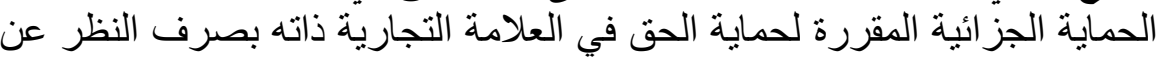

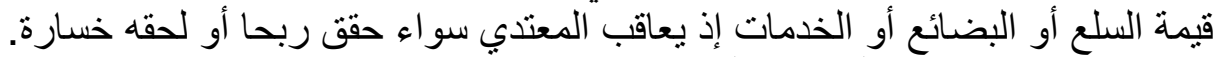

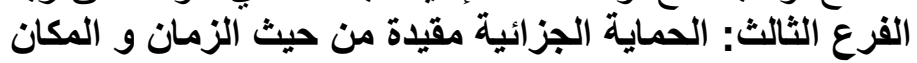

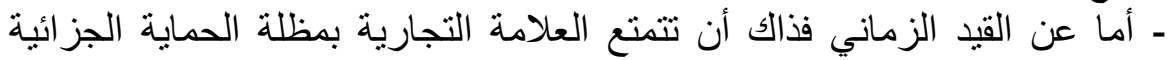

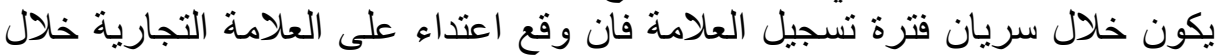
هذه الفترة تقوم الحماية الجزائية و عليه فان الحماية الجزائية للعلامة التجارية تقاية تقوم

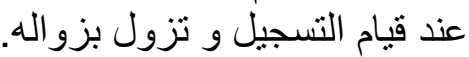
ـ أما عن القيد المكاني فالأصل أن أن الحماية الجزائية للعلامة التجارية مسجلة

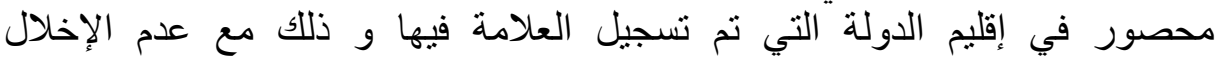

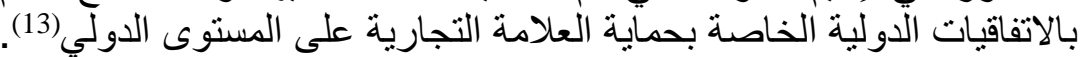
المطلب الثاني: جريمة تقليد العلامات التئة التجارية التجاتية

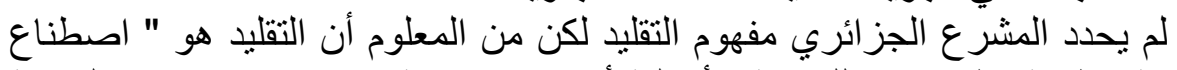

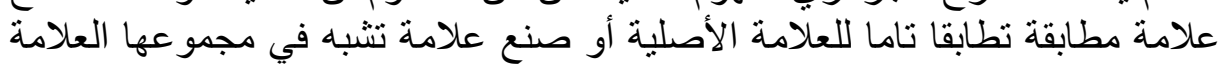


الحقيقية بحيث يمكن للعلامة الجديدة أن تظلل المستهلك و تجذبه إليها ظنا منه أنها العلامة الأصلية " أما التشبيه فهو اصطناع علامة مشابهة بصفة تقريبية للعلامة التانة

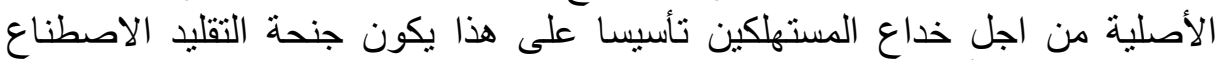

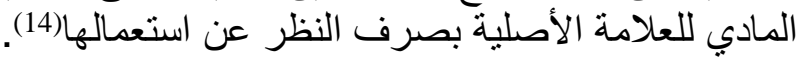

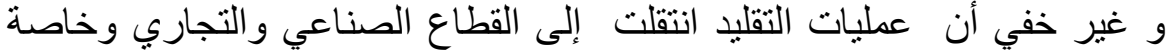

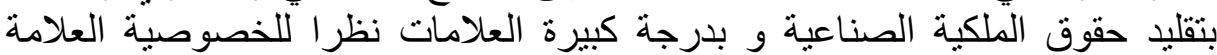

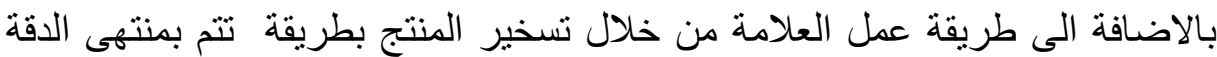

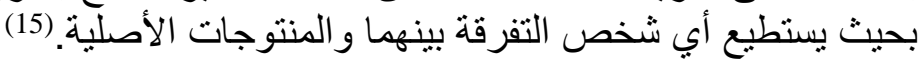
و تقوم جريمة التقليد على 3 أركان :

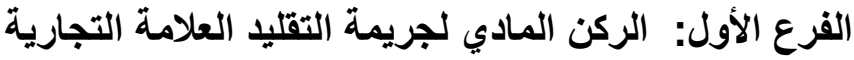

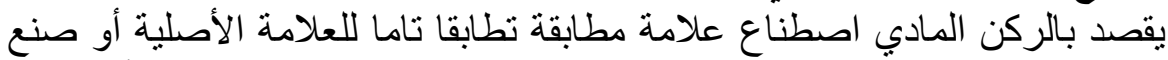

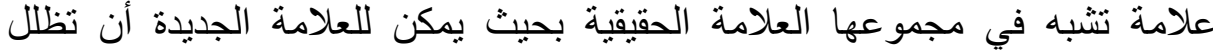

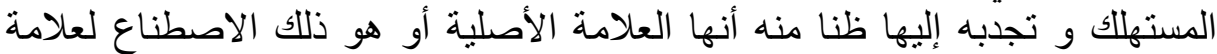

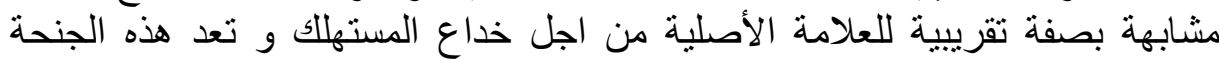
مرتكبة اعتبارا من تاريخ نقل العلامة الأصلية لان عملية الإيداع تكفي في حد ذاتها لإنها

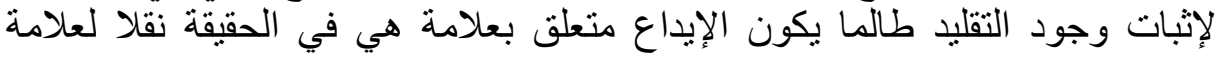

الفرع الثاني: الركن الثرعي لجريمة تقليد العلامة التجارية

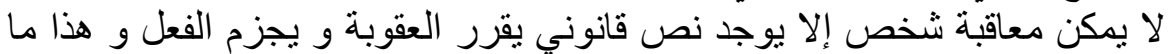

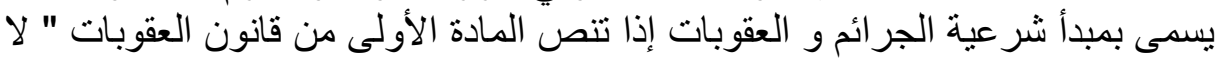
جريمة و لا عقوبة و لا تدبير أمر بغير قانون " و بالرجوع إلى المادة 285 من الأمر

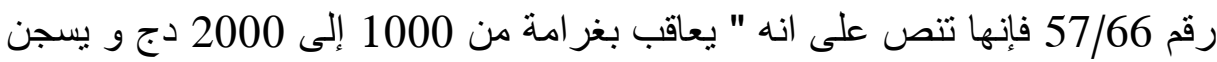
من ثلاثة أثهر إلى ثلاثة سنوات أو بإحدى العقوبتين فقد الذين يقلدون علامة (16)"

الفرع الثالث: الركن المعنوي لجريمة تقليد العلامة التجارية

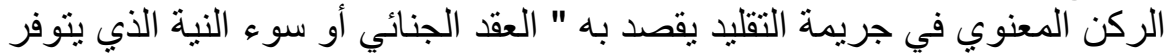

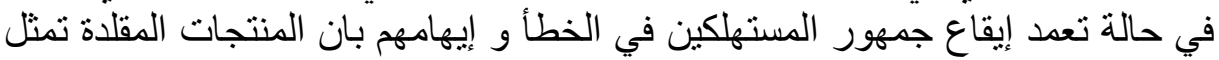

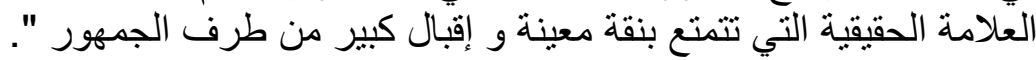

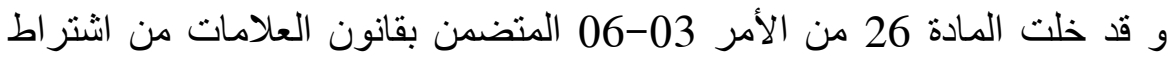

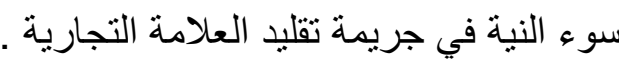

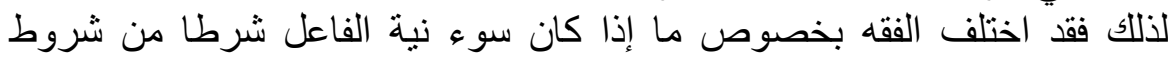

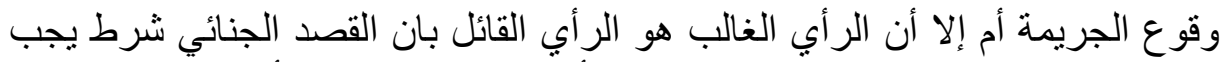

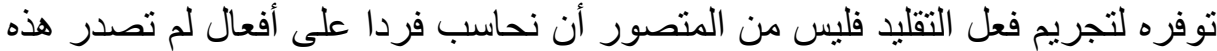

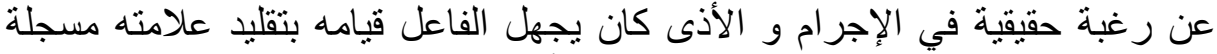

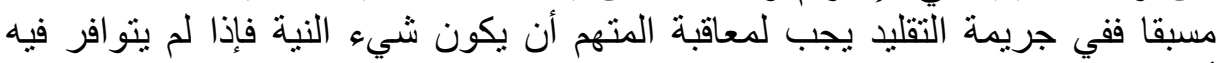

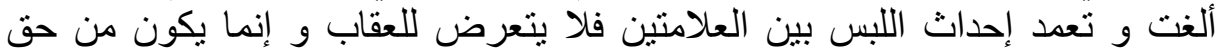

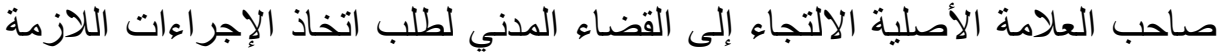

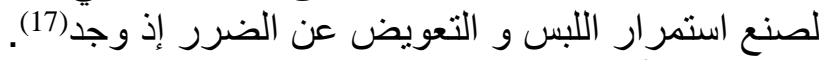

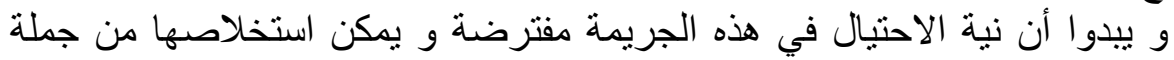

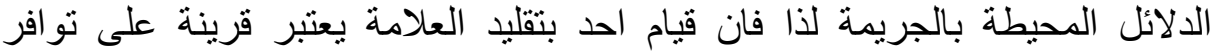

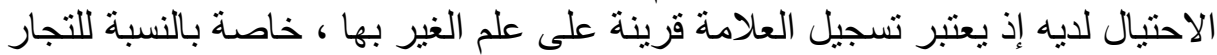

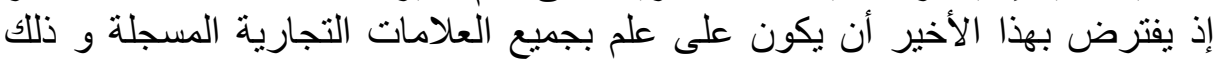
بحكم العرف التجاري فضلا عن أن التقليد لا يمكن اعتباره من باب المصادي المادفة البحثة 
أو التوافق البريء.

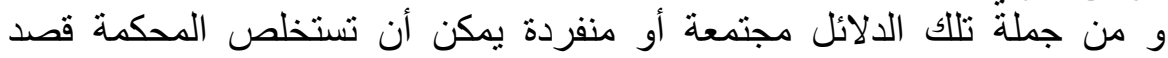

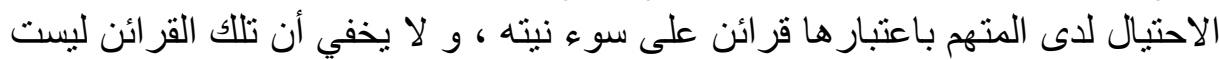

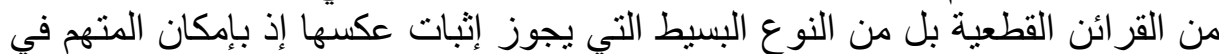

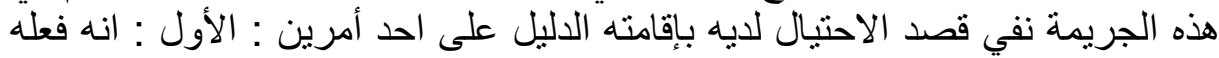

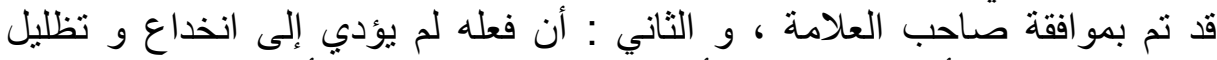

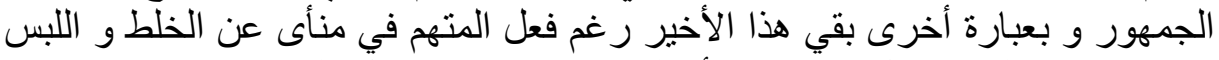

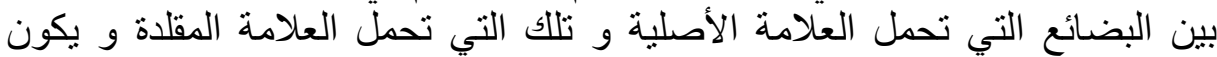

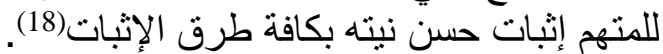

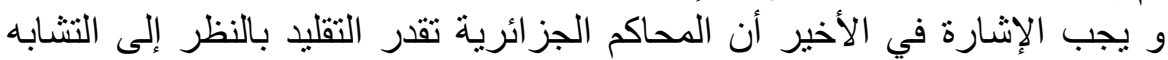

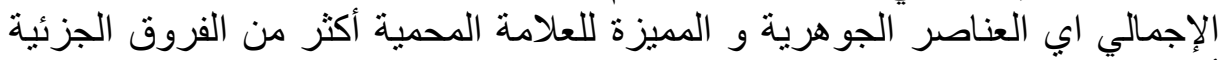

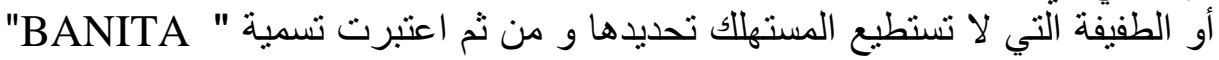

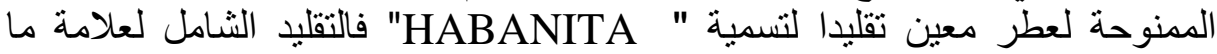

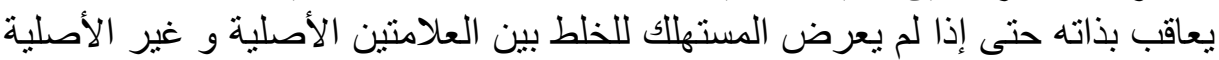

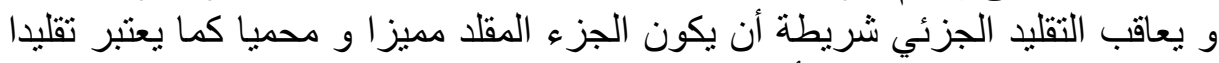

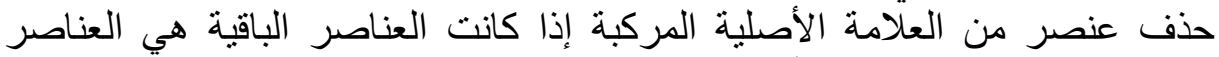

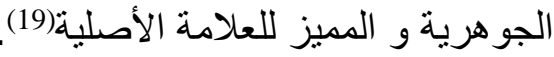
المطلب الثالث :العقوبات الجزية الائية

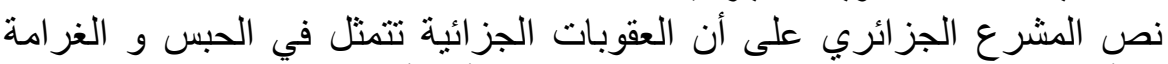

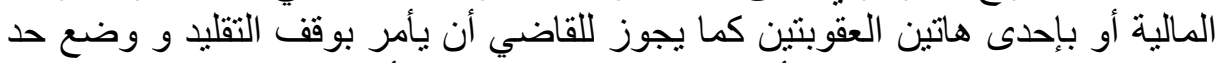

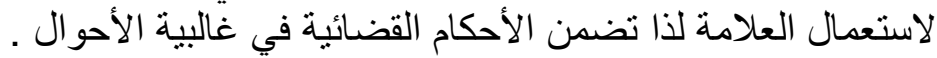

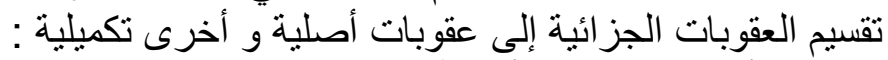
الفرع الأول: العقوبات الأصلية

نص على هذه العقوبات المادة 32 من الأمر 03-06 بالقول :"... كل شخص الاصله ارتكب جنحة تقليد يعاقب بالحبس من ستة (6) أثنهر إلى سنتين و بغر امة من مليونين و خمسمائة ألف دينار ( 2.500 .000 ) إلى عشرة ملايين دينار (10.000.000 إلى دج) أو بإحدى هاتين العقوبتين ....

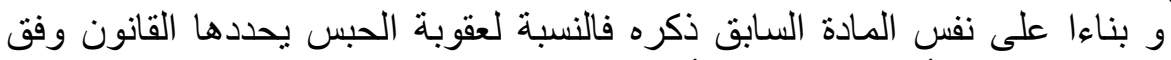

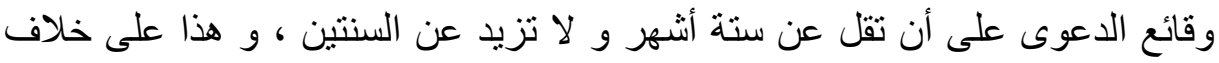

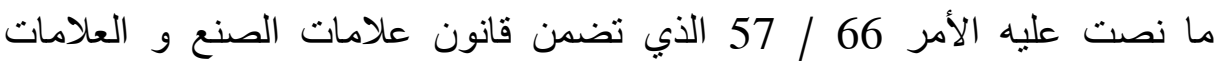

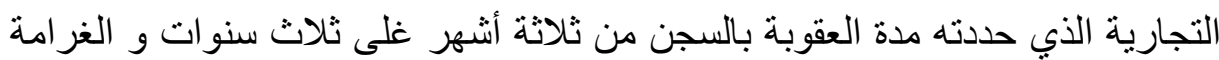

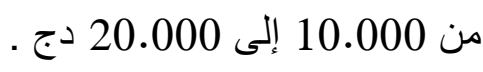
و بذلك يكون المشرع الجزائري قد قام بتخفيض مدة الحبس من ثناثة سنوات إلى إلى إلى

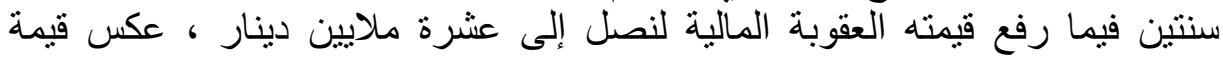

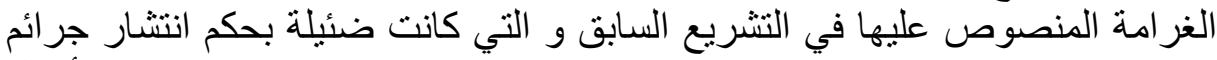

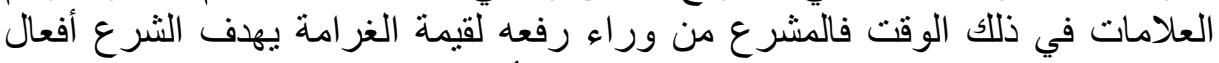

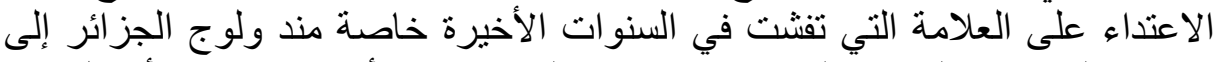

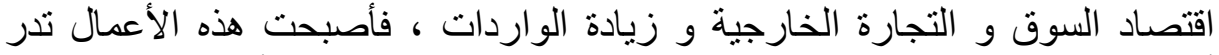

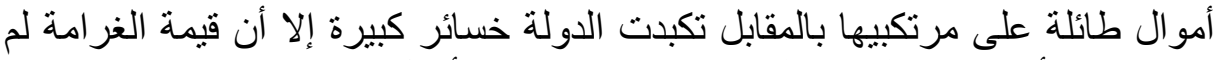

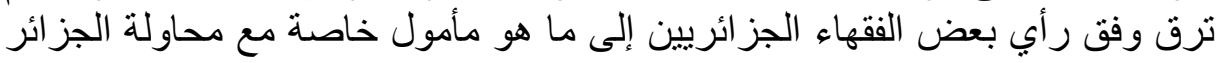

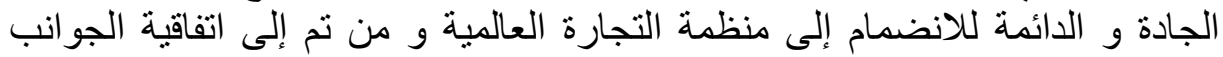


المتعلقة بالتجارة التابعة لمنظمة التجارة العالمية ـ(21)

الفرع الثاني: العقوبات التكميلية

نص عليها المشرع الجزائري من خلال المادة 308 من الأمر 06/03 بالقول مع

الغلق المؤقت أو النهائي للمؤسسة.

ـ مصادرة الأشياء و الوسائل و الأدوات التئي استعملت في المخالفة(22) .

ـ إتلاف الأشياء محل المخالفة.

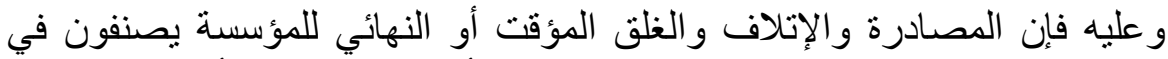

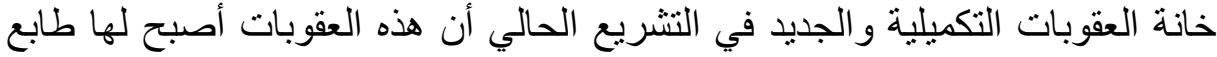

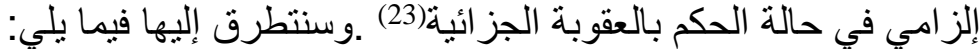

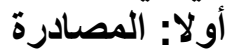

المصادرة لا بد أن تكون بناء على أمر من المحكمة المختصة وقد يكون ذللك أثناء

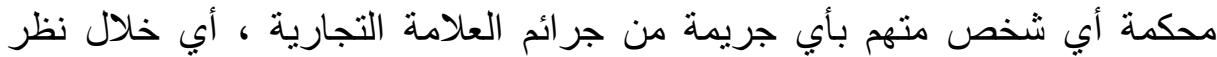

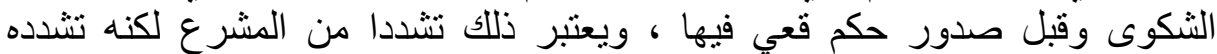

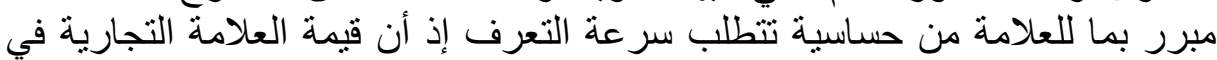

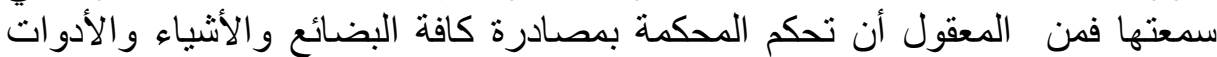

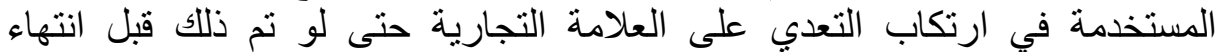

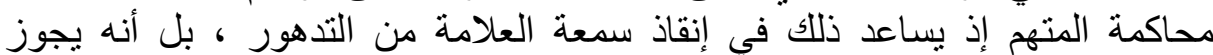

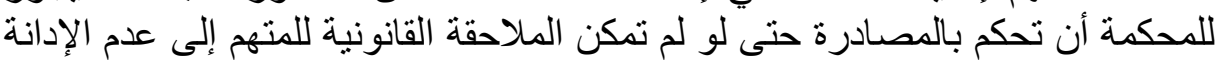
فيما نسب إليه من أفعال تعد على العلامة التجارية.

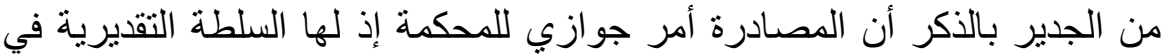

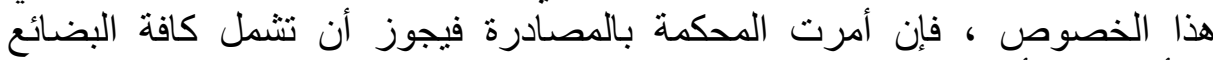

والأدوات والأشياء المستخدمة في ارتكاب الجريمة كما قد تقرر على بعض منها أنسان.

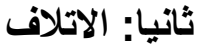

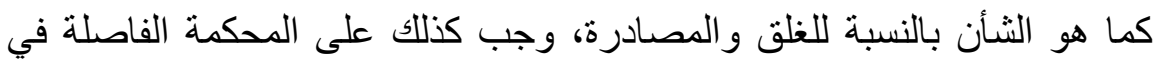

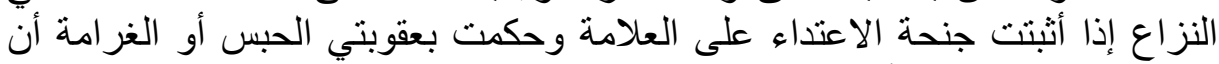

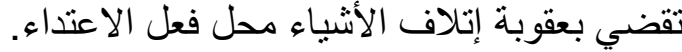
وتثمل الأشياء محل المخالفة المنتجات التي الأي تحمل العلامة المقلدة والوسائل

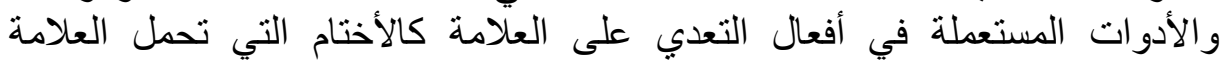

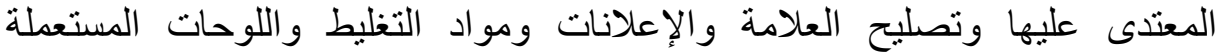

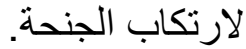

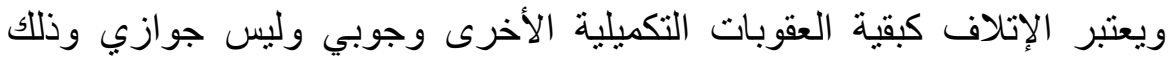

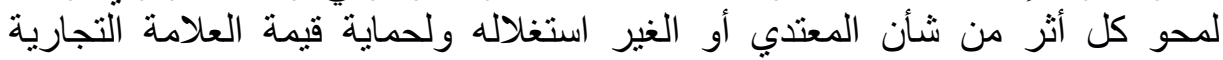

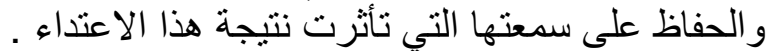

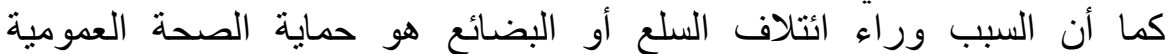

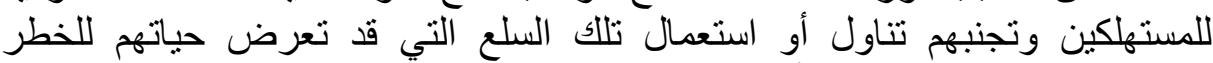

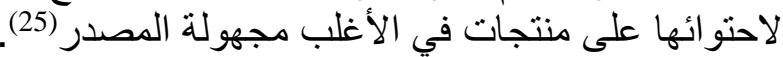

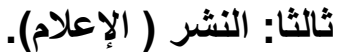
يجوز للقاضي أن يأمر بإلصاق نصان الإنه الحكم في الأماكن التي يحددها كما يجوز لله

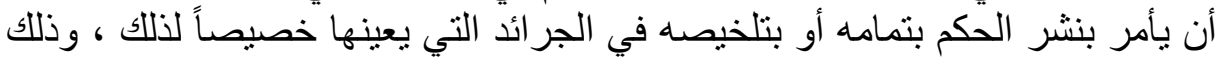

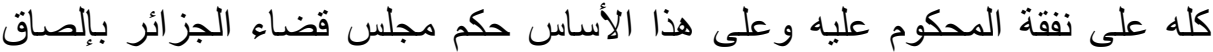

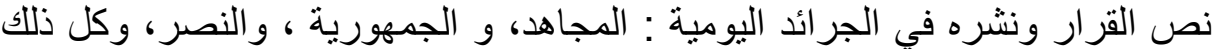
على نفقة المستأنفين. و هذه العقوبة يجوز أن يحكم بها القاضي سواء لصالح المدعي الذي لحق به ضرر 


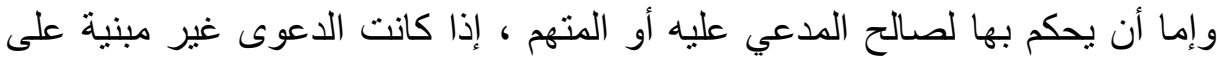

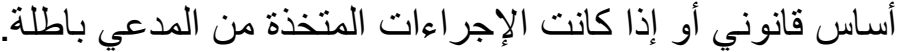

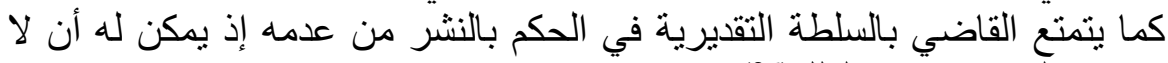

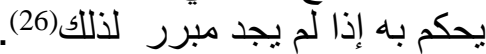
الفرع الثالث: الإجراءات التحفيرة التحية

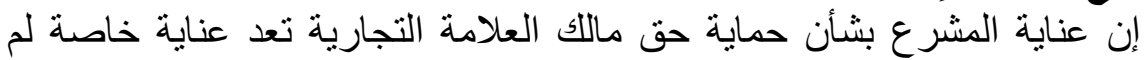

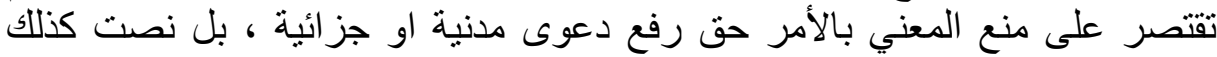

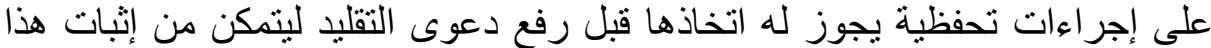
الفعل وفيما يخص الجز اءات فهي مختلفة(27). و عليه يجوز لكل من وقع في اعتداء على حقه في ملكية علامته التجارية أيا كانت

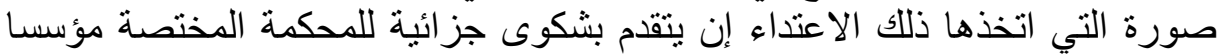

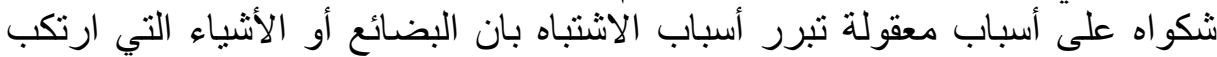
بو اسطتها التعدي موجودة تحت يد المتهم سواء كانت في بيته أو مكان عمله أو أو تحت الته حيازته أو إثر افهه في أي مكان(28)

و قد أجازت المادة 34 من التشريع الجزائري لتمكين المالك من إثبات الجريمة

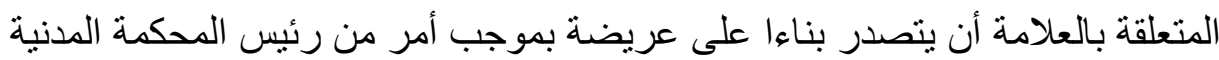

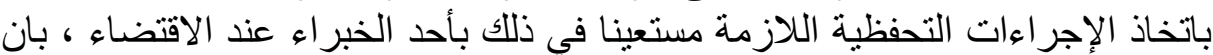

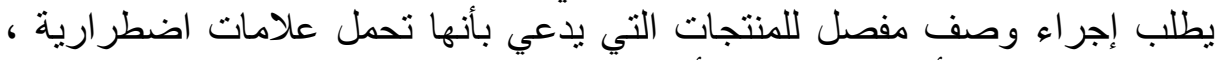

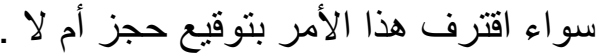

و يشترط أن تكون العريضة مرفقة بما يتبين تسجيل العلامة و يدفع مبلغ الكفالة إذا الذا

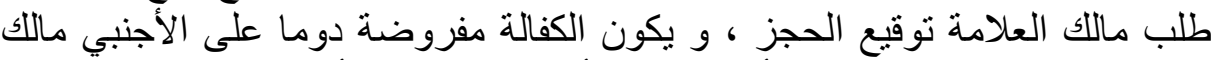

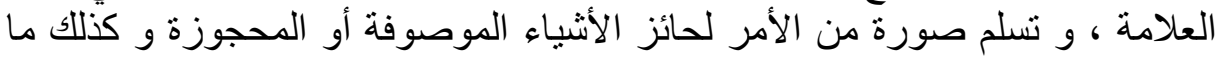

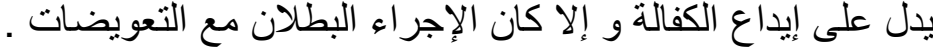

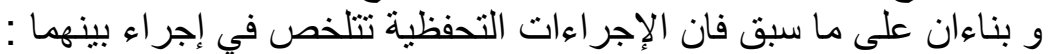

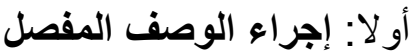

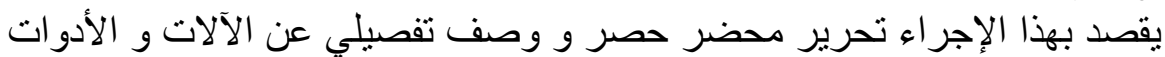

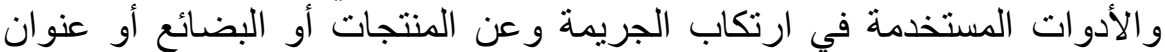

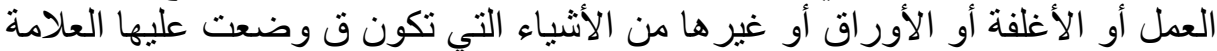

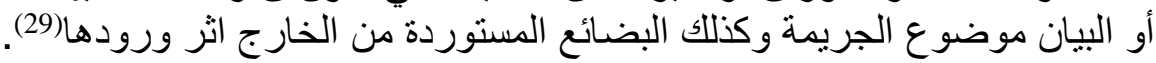
ثانيا: الحجز التحفظي عوني

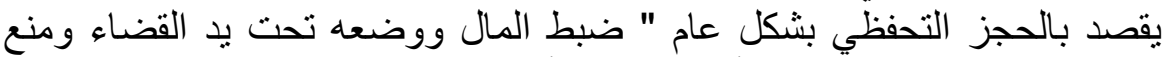

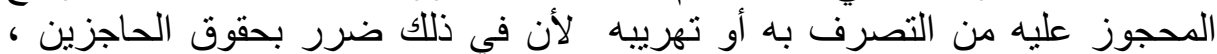

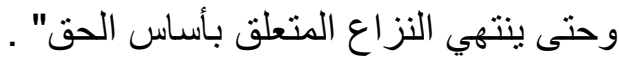

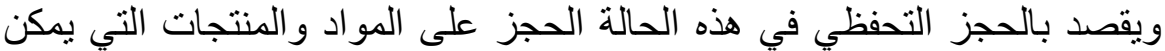

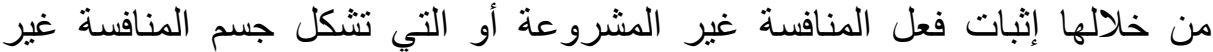

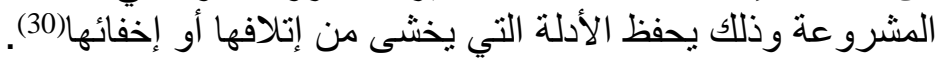

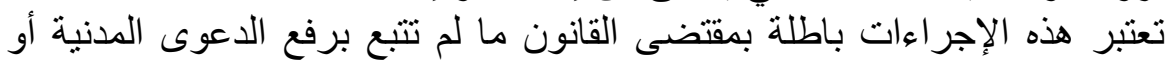

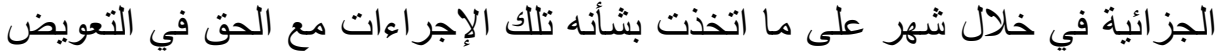
حسب المادة 35 من التشريع المعمول بهابه(31). 


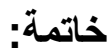

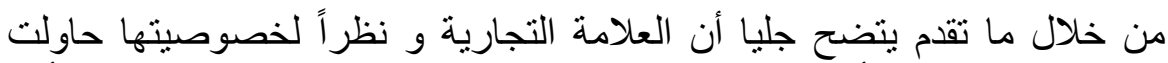

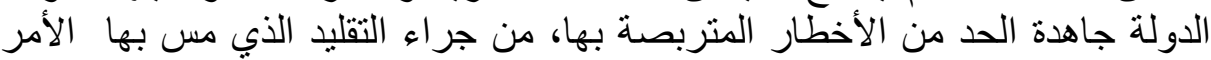

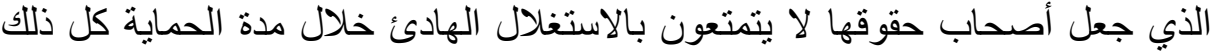

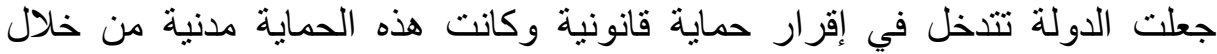

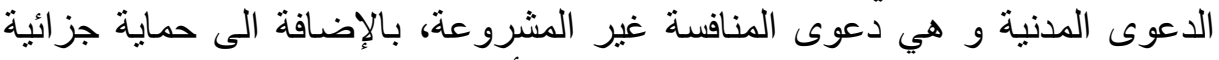

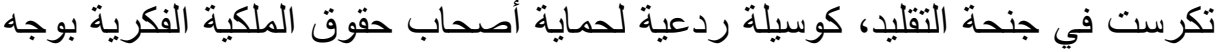

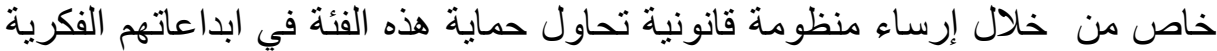

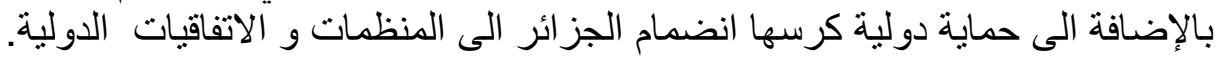

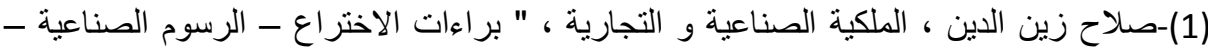

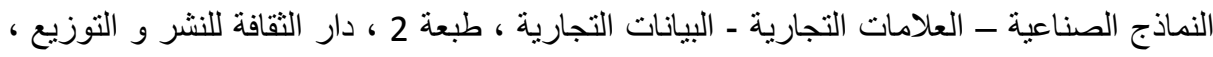

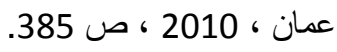

(2)- احمد محرز ، القانون التجاري الجزائري، الجزء الاول، المطبعة العربية الحديثة ، القاهرة ،

1979، ص احمد دمرز ، 201

(3)- سماح محمدي ، الحماية القانونية للعلامات التجارية ، " دراسة المقارنة " رسالة دكتوراه

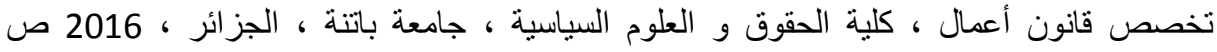

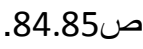

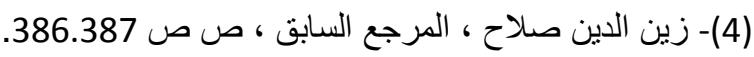

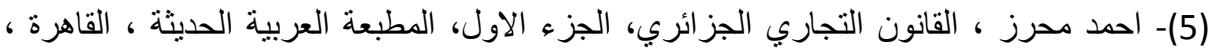

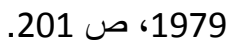

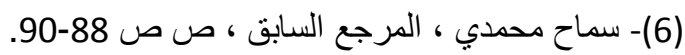

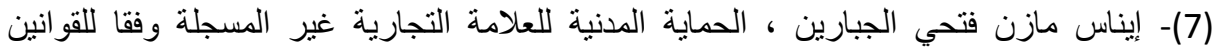

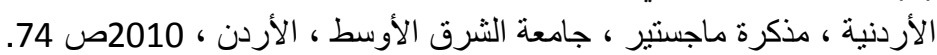

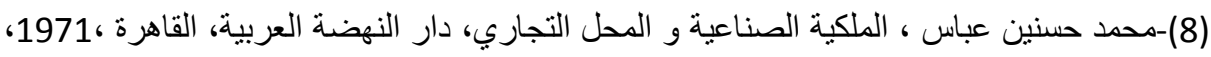

267 ص 267

(9)- زبير حمادي ، الحماية القانونية للعلامات التجارية ، منشور ات الحلبي الحقوقية ، بيروت لبنان ،

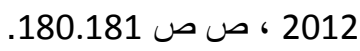

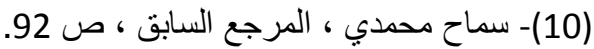

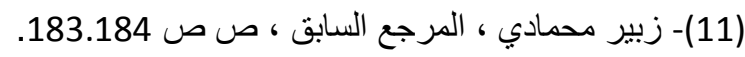

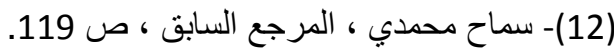

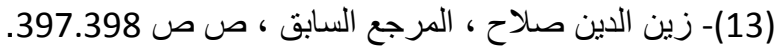

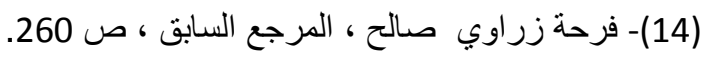

(15)-زرواني نادية، الاعتداء على حق الملكية الفكرية، مذكرة للحصول على شلى شهادة الماجستير، كلية

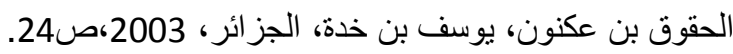

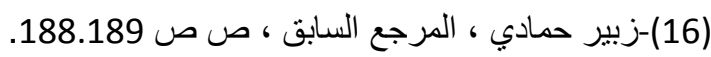

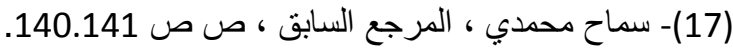

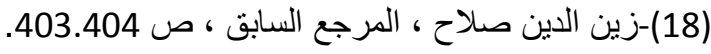

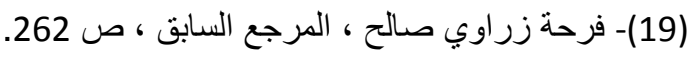

(20)-أنظر المادة 32 من الأمر 03-06 المتعلق بالعلامات الموؤرخ في 19 جويلية 2003 الجريدة

الرسمية عدد 44.

(21)- سماح محمدي ، المرجع السابق ، ص ص 158 ، 159 
(22)-الامر 03-03 السابق ذكره

(23)-فاضلي إدريس، الملكية الصناعية فى القانون الجزائري، الطبعة الثنانية، ديوان المطبوعات

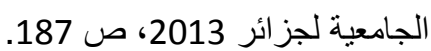

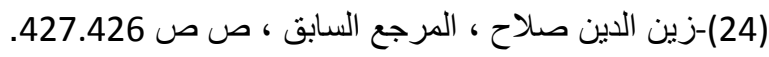

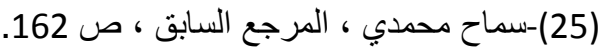

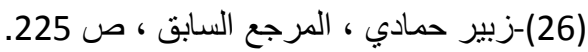

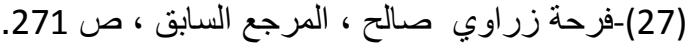

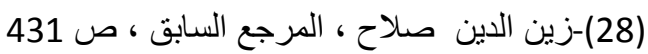

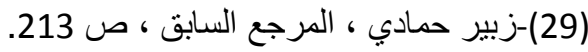

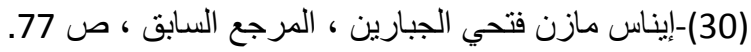

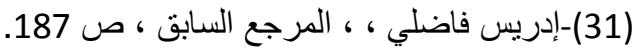

